\title{
Vasoactive neuropeptides and Alzheimer's disease: a systematic review focusing on calcitonin gene-related peptide
}

\author{
Giulio Papiri ${ }^{1}$, Simona Luzzi ${ }^{1,2}$, Matteo Marcucci $^{3}$, Arianna Vignini $^{4, *}$ \\ ${ }^{1}$ Neurology Clinic, Azienda Ospedaliero Universitaria, Ospedali Riuniti di Ancona, 60126 Ancona, Italy \\ ${ }^{2}$ Department of Experimental and Clinical Medicine, Università Politecnica delle Marche, 60126 Ancona, Italy \\ ${ }^{3}$ Radiology Department, Azienda Ospedaliero Universitaria, Ospedali Riuniti di Ancona, 60126 Ancona, Italy \\ ${ }^{4}$ Department of Clinical Sciences, Section of Biochemistry, Biology and Physics, Università Politecnica delle Marche, 60126 Ancona, Italy \\ "Correspondence: a.vignini@univpm.it (Arianna Vignini)
}

DOI:10.31083/j.jin2004107

This is an open access article under the CC BY 4.0 license (https://creativecommons.org/licenses/by/4.0/).

Submitted: 2 September 2021 Revised: 15 September 2021 Accepted: 27 October 2021 Published: 30 December 2021

Vasoactive peptides constitute a heterogenous family of mediators exerting various physiological functions, mostly studied for their vasotropic effects and role as peripheral neurotransmitters/neuromodulators, mainly involved in nociceptive transmission modulation. They have been divided into vasodilatory or vasoconstrictive peptides, according to their predominant effects on vascular tone. Recent research has shown in the Central Nervous System effects as transmitters and "growth factor-like" signals. Therefore, deregulation of their signaling systems has been thought to play a role in neural cell death and in the pathogenesis of neurodegenerative disorders, including Alzheimer's disease, since these peptides can regulate neuronal stress signaling, survival cascades, synaptic plasticity. This review considers evidence about the implication of neuropeptide systems in Alzheimer's disease while focusing mainly on calcitonin gene-related peptide-alpha. In vitro and in vivo studies have shown potential implications in its pathogenesis. It has been possibly proposed as a neuroprotective agent, considering not only its pleiotropic actions on blood vessels, neurovascular coupling, energy metabolism, but also its potential actions on neuronal, glial, and immune system stress signaling, which might also derive from its structural homology to amylin. Amylin signaling is thought to be disrupted in Alzheimer's disease, and amylin itself takes part in the composition of senile plaques. Calcitonin gene-related peptide-containing systems seem more closely related to Alzheimer's disease pathogenesis than other neuropeptidergic systems, and their regulation might represent an interesting mechanism in developing novel therapeutic approaches.

\section{Keywords}

Calcitonin gene-related peptide; Vasodilatory peptides; Vasoconstrictive peptides; Alzheimer's disease

\section{Alzheimer's disease: pathogenesis and current therapeutic options}

This review highlights the potential roles of vasoactive peptides in the pathogenesis of Alzheimer's disease (AD). It is a complex neurodegenerative disease whose most prominent features, on a neuropathological basis, are thought to be atrophy and neuron loss as well as the accumulation in sev- eral cortical areas of pathologic elements like senile plaques, mainly composed of amyloid-beta 1-42 and amylin, and neurofibrillary tangles, mainly composed of hyperphosphorylated tau $[1,2]$.

The precise etiology of this disease remains elusive, albeit its pathogenesis has been extensively studied in several different animal models, which summarize various biological aspects and processes occurring during the disease continuum [3-5]. Numerous biochemical events occur during disease progression, leading to disruption of neuronal and glial housekeeping processes, from lipid signaling [6] to onecarbon metabolism imbalance [7-9], energy metabolism, mitochondrial energy and free radical production [10], calcium homeostasis [11], ultimately resulting in synaptic network failure, which is thought to be responsible for the development of cognitive impairment [12-14]. The disease processes are not thought to be exclusively confined within neurons, since various in vitro and in vivo studies have highlighted the importance of glial and microglial housekeeping and signaling processes [15], as well as their interaction with neurons, in shaping the events leading to the progression of the disease and the development of dementia. Other mechanisms, which have been thought to play a role in the disease continuum are inflammation of the central nervous system (CNS) [16], immune system and vascular dysfunction [17].

Given the neuropathological aspects, the neurotoxicity observed both in vitro and in vivo by various amyloid isoforms, and considering the monogenic forms of this disease, which are caused by mutation of genes involved in amyloid precursor protein (APP) processing (APP, presenilin 1 [PSEN1], presenilin 2 [PSEN2]) [18], much effort has been made to elucidate possible mechanisms linking amyloid processing dysfunction, amyloid and tau accumulation to the development of dementia. Considering data from human neuropathological studies and the paramount importance of amyloid and tau accumulation in animal models of the disease, the amyloid hypothesis was formulated, implying as the major cul- 
prit for the development of dementia, the neurotoxic properties of accumulated senile plaques and neurofibrillary tangles, which over time spread progressively to involve wide areas of the cerebral cortex [19]. In sporadic forms of the disease, data from genomic studies have highlighted an association between genetic loci involved in inflammation, immune response, vesicle and endosome cycling, lipid signaling, cytoskeletal assembly, and susceptibility to disease development $[15,18]$. Therefore, it was theorized that the amyloid cascade triggers the recruitment of other mechanisms over time, such as astroglial and microglial dysfunction, inflammation, neurovascular dysfunction, impairment in growth factor signaling and loss of blood-brain barrier (BBB) integrity [20], leading to impaired brain energy metabolism and synaptic failure. Recent studies have also highlighted a potential association between gut dysbiosis and $\mathrm{AD}$ progression since the gut microbiome regulates inflammation and microglia activation within the CNS. Sodium oligomannate, a drug acting on the gut microbiome, was approved in China in 2019 as a treatment for $\mathrm{AD}[3,21-24]$.

Animal studies reproducing the neuropathological aspects of amyloidopathy and tauopathy have stressed the importance of amyloid-beta and tau removal as potential therapeutic approaches [25]. Amyloid-plaque targeted therapies have yielded encouraging results in animal models. In contrast, in human subjects they have been shown to bind and demolish amyloid plaques effectively, while conflicting results have been obtained about their effectiveness on cognitive impairment $[26,27]$.

Despite the conflicting evidence, in June 2021, aducanumab, a monoclonal antibody targeting insoluble amyloid-beta fibrils, was approved for use in AD patients in the United States. A possible explanation of the heterogeneous results of human trials might depend on the fact that those drugs might be maximally effective in a presymptomatic phase since $\mathrm{AD}$ begins to develop several decades before symptom onset. However, the DIAN-TU-001 trial, investigating the effectiveness of gantenerumab and solanezumab, monoclonal antibodies targeting mainly senile plaques and amyloid-beta oligomers (ABOs), in symptomatic and presymptomatic autosomal dominant $\mathrm{AD}$ mutation carriers has failed to meet its clinical efficacy endpoints. It has been stopped before its completion [28].

These observations, as well as a not perfectly consistent correspondence between the entity of neuropathological involvement and cognitive impairment, as well as the frequent observation of tau deposition in the absence of amyloid deposition in areas of degeneration and atrophy, have led to reconsider various aspects of the amyloid hypothesis under a wider perspective. In fact, since other varieties of amyloid-beta, such as ABOs, show an accumulation profile more consistent with hyperphosphorylated tau aggregates, their pathogenic role is being studied with an increasing interest [19, 29]. Considering the observed heterogeneity in progression, it could be reasonable to assume that many other processes might concurrently influence phenotypic progression during disease development, besides neuronal and glial loss. As for symptoms, they are thought to be more closely related to neurotransmission and energy failure within the CNS [30].

Fast neurotransmission, represented by excitatory and inhibitory amino acids (glutamate and gamma-aminobutyric acid-GABA), has been extensively studied in various disease models. In $\mathrm{AD}$, excitotoxic phenomena are thought to occur. Drugs, such as memantine, which are thought to ameliorate abnormal glutamatergic signaling, have elicited a moderate, albeit temporary, symptom relief [31-33].

\section{Vasoactive peptides in AD: overview}

CNS neuropeptide signaling has received less attention than fast neurotransmission. Among these neuropeptides, vasoactive peptides, which can be distinguished in vasodilatory (for instance, brain natriuretic peptide, substance $P$, calcitonin gene-related peptide) or vasoconstrictors (for instance, endothelin-1) according to their preponderant vascular effects, are being increasingly recognized, due to their pleiotropic actions on vascular physiology, inflammation, immune homeostasis, as well as their neurotransmitter role in both the central and peripheral nervous system (PNS), as possibly implied in the disease processes [34]. As neurotransmitters, neuropeptides are thought to be released from large dense-core vesicles (LDCV) and act on wider ranges and time scales than amino acid neurotransmitters; their recycling steps are not as well characterized as for fast neurotransmitters, although active reuptake processes have been hypothesized [35, 36]. Among their effects on neurotransmission, some neuropeptides have been found to regulate monoaminergic circuits, such as pituitary adenylate cyclaseactivating polypeptide (PACAP), neurotensin and calcitonin gene-related peptide (CGRP) [37-39]. Vasoactive neuropeptides are linked to neurotransmission modulation and synaptic plasticity and possess growth-factor secretagogue properties, while also exerting complex regulatory effects on inflammation and immune cell activation and secretion cascades.

Among the possible mechanisms underlying the potential pathogenic role of neuropeptides in $\mathrm{AD}$, balance between vasodilatory and vasoconstrictor signals might play a role. Amyloid-beta 1-42 has been shown to engage with nanomolar affinity several cell membrane targets, including alfa-1 adrenoceptors, acting as a central as well as a peripheral vasoconstrictor [40, 41]. Endothelin-1, which is a potent vasoconstrictor, has been shown to disrupt hippocampal protein synthesis and to produce memory impairment in mice [42]. Neuropeptides with pronounced vasodilatory effects such as vasoactive intestinal peptide (VIP), PACAP, neuropeptide Y, substance $\mathrm{P}$, neurotensin and orexin-1, have been studied both in vitro and in vivo and have been shown to ameliorate amyloid toxicity, regulate hippocampal plasticity and influence $\mathrm{AD}$ pathology by recruiting multiple intracellular mechanisms. Such mechanisms, including non-amyloidogenic and $\mathrm{A} \beta$-degrading cascades activation, neurotrophin production, 


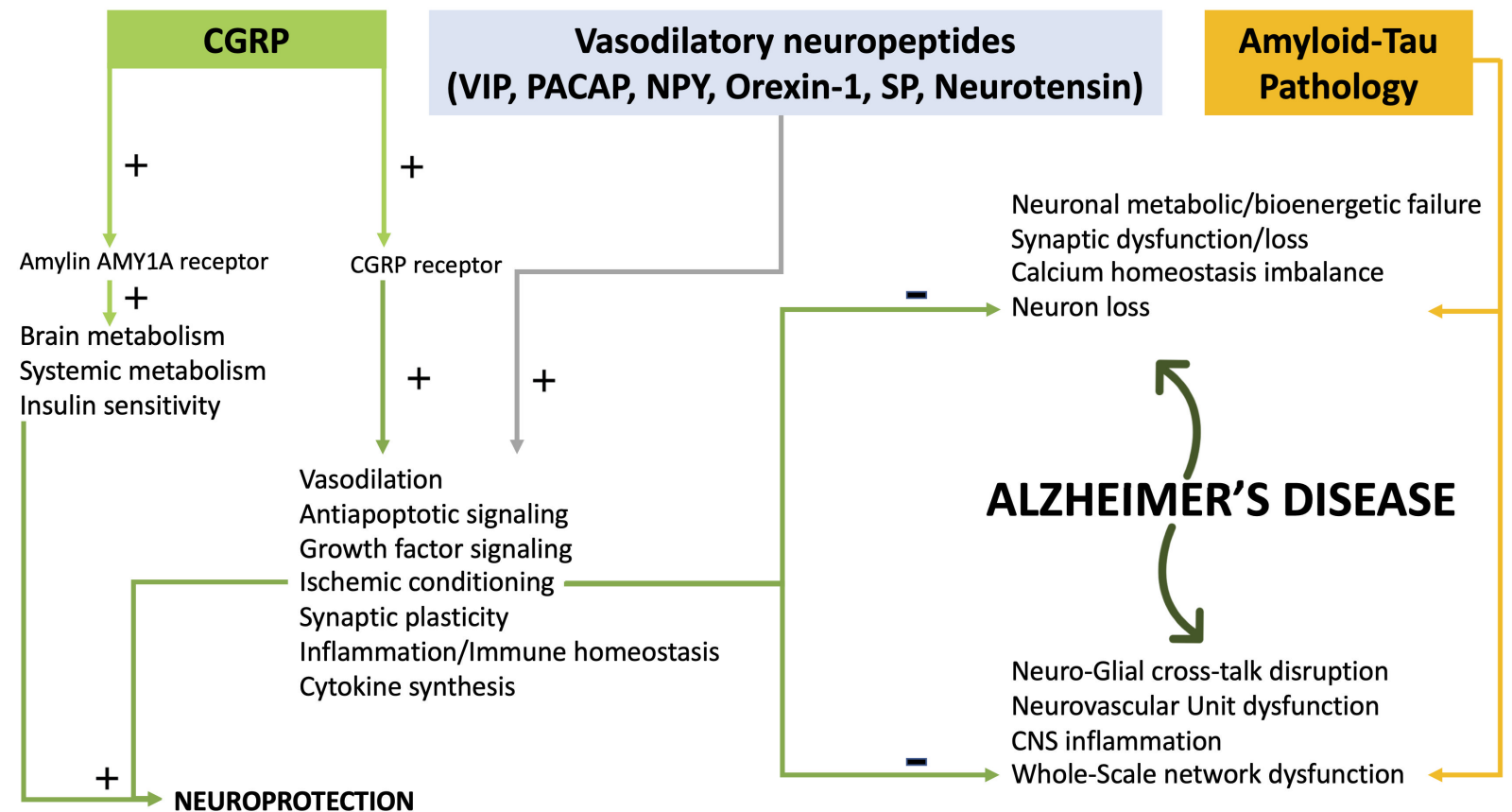

Fig. 1. Synopsis of potential neuroprotective mechanisms exerted by calcitonin gene-related peptide (CGRP) and vasodilatory neuropeptides on Alzheimer's disease $(\mathrm{AD})$ pathogenesis.

neuronal glucose uptake increase, antiapoptotic pathway (such as NF- $\kappa$ B, PI3K-Akt, MAPK, Jak-STAT, ERK $1 / 2$ phosphorylation) upregulation, endoplasmic reticulum stress and autophagy inhibition, LTP and potassium channel activity modulation, have emerged as possible neuropeptides' downstream effectors in $\mathrm{AD}$ [43].

Among these, VIP and PACAP have been studied most thoroughly in neurodegenerative diseases and have been linked to AD and Parkinson's Disease pathogenesis [44-46]. PACAP has also been linked to a potential pathogenetic role due to its effects on immune cell polarization and signaling in Multiple Sclerosis animal models [47]. Altogether, considering their effects, these neuropeptides, as mentioned earlier, are being considered as potential therapeutic targets in neurodegenerative conditions. Despite this, CGRP has received less attention in this regard, although existing data point to a possible link with $\mathrm{AD}$ pathogenesis [38].

\section{CGRP: general physiology and influence on AD pathogenesis}

CGRP, existing in two isoforms, alpha and beta, encoded by different genes (CALCA and CALCB), has been associated since its discovery, together with substance $\mathrm{P}$, to a crucial role in sensory and nociceptive neurotransmission and in the pathophysiology of migraine $[48,49]$. Its functions in the CNS have been less thoroughly studied, though it is a widely distributed ubiquitary peptide in the CNS [50].

It belongs to a family of neuropeptides which comprises adrenomedullin, amylin, intermedin and calcitonin [51]. It exerts its effects by activating its receptor, which belongs to the superfamily of transmembrane $\mathrm{G}$ protein-coupled receptors [52]. Its signal transduction mechanisms have been found in multiple experimental contexts to recruit different cascades, giving rise to the hypothesis of tissue-specific signaling [53]. Apart from its canonical receptor, which is a heteromeric protein made from the assembly of the calcitoninlike receptor (CLR) and receptor activity-modifying protein 1 (RAMP1), CGRP-alpha is thought to be able to activate, with high affinity, type $1 \mathrm{~A}$ amylin receptors, while on the other hand adrenomedullin might exhibit a low affinity towards CGRP receptors [54].

$\mathrm{G}_{s}$ signaling, starting cAMP-dependent cascades, is thought to be the preponderant signal transduction pathway of the CGRP receptor; furthermore, CGRP receptors may also associate with an accessory subunit named receptor component protein (RCP) $[51,55,56]$.

In the CNS, CGRP-alpha producing neurons and CGRP receptors are widely distributed, although their territories do not overlap. CGRP receptor synthesis is considered to be quantitatively predominant in subcortical structures. These findings appear in line with data on neuropeptide synthesis and expression since neuropeptide synthesis and release are not thought to be confined only to synaptic specializations and are also thought to play a modulating role on synaptic activity through "volume transmission", which can take place on longer distances than fast synaptic transmission $[35,57]$.

As for general neuropeptide biology, albeit the conserved and shared pleiotropic actions, CGRP might hold a privileged position in $\mathrm{AD}$ pathogenesis if a few experimental observations are considered. 
CGRP-alpha is released in response to various stressful stimuli and favors neuronal survival in several cell injury models, such as brain ischemia-reperfusion injury. Therefore, it has been defined as a possible mediator of ischemic preconditioning [58]; furthermore, in relation to its potent vasodilatory activity, it is thought to be protective against cerebral vasospasm (Fig. 1) [59].

$\mathrm{AD}$ is increasingly recognized as a disease linked to vascular dysfunction, inflammation and immune dysfunction; recent studies also indicate a potential association with migraine [22, 60, 61]. CGRP-alpha represents a pleiotropic agent which might exhibit context-dependent differential effects on immune activation. It appears as a potent proinflammatory agent in the PNS, where it drives neurogenic inflammation and stimulates growth factor production in glial elements, such as in migraine [62, 63].

On the other hand, it might also stimulate complex responses in dendritic cells, where appears to regulate TLR signaling dampening cytokine production [64]. It seems to play a similar anti-inflammatory role in the CNS, where intrathecal injection of CGRP can ameliorate disease phenotype in animal models of Multiple Sclerosis [65]. Vasoactive peptides, including CGRP-alpha, are regarded as regulators of gut microbiome composition, as they possess natural antibacterial properties, which are thought to derive from their cationic physical-chemical properties [66, 67].

CGRP-alpha has been found to benefit synaptic plasticity, mainly through the induction of cAMP-dependent pathways [68]. It has also been found to stimulate hippocampal neurogenesis and angiogenesis [38]. These observations have strengthened the notion that it might be involved in cognitive and mood disorders [69]. Data coming from experiments on intracerebroventricular injection in murine models have associated CGRP-alpha release to profound behavioral changes deriving from an influence on monoaminergic projections [70]. CGRP-alpha in cerebral spinal fluid (CSF) in human subjects appears to be produced in loco and independently from plasma levels, as CGRP might not efficiently cross the $\mathrm{BBB}$ in physiological conditions [71]. Increased CGRP-alpha CSF concentration has been detected in depressed subjects, while decreased CGRP-alpha CSF concentration has been detected in a small cohort of subjects affected by degenerative dementias (AD or frontotemporal dementia). A possible explanation for their finding is that CGRP-alpha CSF concentration might reflect brain atrophy. However, the possibility that it might reflect upstream neurodegenerative progress or synaptic dysfunction has not been ruled out yet [72, 73].

Donepezil, a reversible acetylcholinesterase inhibitor and one of the drugs approved to treat $\mathrm{AD}$ symptoms, has been found to increase hippocampal neurogenesis and angiogenesis. This effect is abolished in CGRP-alpha knockout mice [74].

From an anatomical perspective, it should also be considered that the parabrachial nucleus, containing CGRP producing neurons, sends projections to cholinergic basal nuclei, whose functioning is impaired in AD; furthermore, CGRPalpha is thought to exert a modulatory action on central nicotinic receptors $[75,76]$.

In a recent study by $\mathrm{Na}$ and colleagues, $5 \mathrm{xFAD}$ mice were treated with olcegepant, a CGRPalpha-receptor antagonist; treated mice showed an amelioration of the disease phenotype, especially if treatment was started at a younger age [77]. The observation of an age-dependent effect might, in the first place, speculatively point to a potentially differential involvement of CGRPergic circuits in the early phases of the disease. Disruption of the BBB, which appears in humans to increase with worsening cognition, might have partially driven the observed effect, and plasma CGRP itself might help preserve BBB integrity $[62,78]$. Furthermore, being structurally related to amylin and mediating high-affinity activation of AMY 1A receptors, it could be speculated that blocking CGRP receptors might reinforce amylin signaling through a "spill-over" mechanism. It is not yet possible to rule out this hypothesis since direct CGRP-alpha blockade has not been so far tested in AD animal models.

CGRP does not appear to act only on neurons but also regulates glial activation and signaling processes within the brain since knockout mice for CGRP show larger ischemic lesions and increased astroglial activation and inflammation [58]. Amylin has been found, as well, to ameliorate proinflammatory cross-talk between glial elements [79]. The tight relationship between CGRP and Amylin strengthens the hypothesis of a role of the former in AD pathogenesis since amylin takes part in amyloid plaques' composition, has been found to exert protective actions in various experimental models of $\mathrm{AD}$ and is also implied in amyloid-beta clearance [80]. On the other hand, both Amylin and CGRP are tightly linked to brain and systemic energy metabolism regulation, exocrine pancreas secretion, insulin signaling, feeding behavior, and satiety. They have thus been implied in Type II Diabetes Mellitus pathogenesis [81, 82].

CGRP, amylin and amyloid-beta also share some of their degradation pathways. CGRP and amyloid-beta can be metabolized by neprilysin, angiotensin-converting enzyme (ACE), endothelin converting enzymes (ECE) and insulindegrading enzyme (IDE), while amylin is degraded mainly by IDE [83, 84]. CGRP, along with amylin, might thus serve a role in modulating the effects of amyloid-beta and tau on the nerve and glial cells and the inflammatory reactions in the nearby environment. From a wider perspective, CGRP, being one of the most potent vasodilators known, might also be implied in the maintenance of neurovascular unit integrity and cerebral autoregulation, in addition to preserving BBB integrity.

\section{Concluding remarks}

CGRP-alpha represents a pleiotropic ubiquitary mediator involved in various physiological processes. Despite the analogies, as for general physiologic and potential neuroprotective properties, with several neuropeptides, data from cel- 
lular studies, animal models and anatomical and biomarker human studies seem to pinpoint a possible complex role in $\mathrm{AD}$ pathogenesis, which derives from the combination of cytoprotective, antiapoptotic actions, with its vasodilatory, vasoprotective and immunoregulatory properties as well as its role as a neurotransmitter.

This wealth of functions, as well as the complexity of its receptor transduction cascades, might perhaps underlie tissue-specific signaling. These features define it as an interesting molecule that might impact several processes within the disease continuum, albeit downstream of the primary cause, therefore defining it as a possible candidate for therapeutic purposes.

\section{Abbreviations}

$\mathrm{A} \beta$, amyloid-beta; $\mathrm{ABO}$, amyloid-beta oligomers; $\mathrm{ACE}$, angiotensin-converting enzyme; AD, Alzheimer's disease; AMY, amylin; APP, amyloid precursor protein; BBB, blood-brain barrier; cAMP, cyclic adenosine monophosphate; CGRP-alpha, calcitonin gene-related peptide alpha; CLR, calcitonin-like receptor; CNS, central nervous system; DIAN-TU-001, Dominantly Inherited Alzheimer Network Trial, An Opportunity to Prevent Dementia. A Study of Potential Disease-Modifying Treatments in Individuals at Risk for or With a Type of Early Onset Alzheimer's Disease Caused by a Genetic Mutation; ECE, endothelin converting enzymes; $\mathrm{ERK}_{1 / 2}$, extracellular signal-regulated kinase; GABA, gamma-aminobutyric acid; $G_{s}$, G stimulatory protein; IDE, insulin-degrading enzyme; Jak-STAT, Janus kinase-signal transducer and activator of transcription; LDCV, large dense-core vesicles; LTP, long-term potentiation; MAPK, mitogen-activated protein kinase; NF-kB, nuclear factor kappa-light-chain-enhancer of activated B cells; PACAP, pituitary adenylate cyclase-activating peptide; PI3KAkt, phosphatidylinositol 3 kinase-AKT kinase; PNS, peripheral nervous system; PSEN1, presenilin 1; PSEN2, presenilin 2; RAMP1, receptor activity-modifying protein 1 ; RCP, receptor component protein; TLR, toll-like receptor; VIP, vasoactive intestinal polypeptide.

\section{Author contributions}

Conceptualization-GP; writing-original draft preparation-GP and MM; writing-review and editing-AV and SL; supervision-AV and SL. All authors have read and agreed to the published version of the manuscript.

\section{Ethics approval and consent to participate}

Not applicable.

\section{Acknowledgment \\ Not applicable.}

\section{Funding}

This research received no external funding.

\section{Conflict of interest}

The authors declare no conflict of interest.

\section{References}

[1] Braak H, de Vos RA, Jansen EN, Bratzke H, Braak E. Neuropathological hallmarks of Alzheimer's and Parkinson's diseases. Progress in Brain Research. 1998; 117: 267-285.

[2] Braak H, Braak E. Staging of Alzheimer's disease-related neurofibrillary changes. Neurobiology of Aging. 1995; 16: 271-284.

[3] De Strooper B, Karran E. The Cellular Phase of Alzheimer's Disease. Cell. 2016; 164: 603-615.

[4] Nazem A, Sankowski R, Bacher M, Al-Abed Y. Rodent models of neuroinflammation for Alzheimer's disease. Journal of Neuroinflammation. 2015; 12: 74 .

[5] Ding Y, Ren J, Yu H, Yu W, Zhou Y. Porphyromonas gingivalis, a periodontitis causing bacterium, induces memory impairment and age-dependent neuroinflammation in mice. Immunity \& Ageing. 2018; 15: 6.

[6] Mielke MM, Haughey NJ, Han D, An Y, Bandaru VVR, Lyketsos CG, et al. The Association between Plasma Ceramides and Sphingomyelins and Risk of Alzheimer's Disease Differs by Sex and APOE in the Baltimore Longitudinal Study of Aging. Journal of Alzheimer's Disease. 2017; 60: 819-828.

[7] Zhuo J, Wang H, Praticò D. Is hyperhomocysteinemia an Alzheimer's disease (AD) risk factor, an AD marker, or neither? Trends in Pharmacological Sciences. 2011; 32: 562-571.

[8] Li JG, Chu J, Barrero C, Merali S, Praticò D. Homocysteine exacerbates $\beta$-amyloid pathology, tau pathology, and cognitive deficit in a mouse model of Alzheimer disease with plaques and tangles. Annals of Neurology. 2014; 75: 851-863.

[9] Di Meco A, Li J, Barrero C, Merali S, Praticò D. Elevated levels of brain homocysteine directly modulate the pathological phenotype of a mouse model of tauopathy. Molecular Psychiatry. 2019; 24: 1696-1706.

[10] Blass JP. Brain metabolism and brain disease: Is metabolic deficiency the proximate cause of Alzheimer's dementia? Journal of Neuroscience Research. 2001; 66: 851-856.

[11] Marambaud P, Dreses-Werringloer U, Vingtdeux V. Calcium signaling in neurodegeneration. Molecular Neurodegeneration. 2009; 4: 20.

[12] Selkoe DJ. Alzheimer's disease is a synaptic failure. Science. 2002; 298: 789-791.

[13] Bell KFS, Hardingham GE. The influence of synaptic activity on neuronal health. Current Opinion in Neurobiology. 2011; 21: 299-305.

[14] Kashyap G, Bapat D, Das D, Gowaikar R, Amritkar RE, Rangarajan $\mathrm{G}$, et al. Synapse loss and progress of Alzheimer's disease -a network model. Scientific Reports. 2019; 9: 6555.

[15] Tansey KE, Cameron D, Hill MJ. Genetic risk for Alzheimer's disease is concentrated in specific macrophage and microglial transcriptional networks. Genome Medicine. 2018; 10: 14.

[16] De Luca C, Colangelo AM, Alberghina L, Papa M. Neuro-Immune Hemostasis: Homeostasis and Diseases in the Central Nervous System. Frontiers in Cellular Neuroscience. 2018; 12: 459.

[17] Li J, Praticò D. High levels of homocysteine results in cerebral amyloid angiopathy in mice. Journal of Alzheimer's Disease. 2015; 43: 29-35.

[18] Van Cauwenberghe C, Van Broeckhoven C, Sleegers K. The genetic landscape of Alzheimer disease: clinical implications and perspectives. Genetics in Medicine. 2016; 18: 421-430.

[19] Selkoe DJ, Hardy J. The amyloid hypothesis of Alzheimer's disease at 25 years. EMBO Molecular Medicine. 2016; 8: 595-608.

[20] Mufson EJ, Counts SE, Ginsberg SD, Mahady L, Perez SE, Massa SM, et al. Nerve Growth Factor Pathobiology During the Progression of Alzheimer's Disease. Frontiers in Neuroscience. 2019; 13: 533.

[21] Hill JM, Clement C, Pogue AI, Bhattacharjee S, Zhao Y, Lukiw WJ. Pathogenic microbes, the microbiome, and Alzheimer's dis- 
ease (AD). Frontiers in Aging Neuroscience. 2014; 6: 127.

[22] Montagne A, Nation DA, Pa J, Sweeney MD, Toga AW, Zlokovic BV. Brain imaging of neurovascular dysfunction in Alzheimer's disease. Acta Neuropathologica. 2016; 131: 687-707.

[23] Wang X, Sun G, Feng T, Zhang J, Huang X, Wang T, et al. Sodium oligomannate therapeutically remodels gut microbiota and suppresses gut bacterial amino acids-shaped neuroinflammation to inhibit Alzheimer's disease progression. Cell Research. 2019; 29: 787-803.

[24] Xiao S, Chan P, Wang T, Hong Z, Wang S, Kuang W, et al. A 36week multicenter, randomized, double-blind, placebo-controlled, parallel-group, phase 3 clinical trial of sodium oligomannate for mild-to-moderate Alzheimer's dementia. Alzheimer's Research \& Therapy. 2021; 13: 62.

[25] Poon CH, Wang Y, Fung M, Zhang C, Lim LW. Rodent Models of Amyloid-Beta Feature of Alzheimer's Disease: Development and Potential Treatment Implications. Aging and Disease. 2020; 11: 1235.

[26] Honig LS, Vellas B, Woodward M, Boada M, Bullock R, Borrie M, et al. Trial of Solanezumab for Mild Dementia Due to Alzheimer's Disease. The New England Journal of Medicine. 2018; 378: 321330.

[27] Panza F, Lozupone M, Logroscino G, Imbimbo BP. A critical appraisal of amyloid- $\beta$-targeting therapies for Alzheimer's disease. Nature Reviews Neurology. 2019; 15: 73-88.

[28] Plotkin SS, Cashman NR. Passive immunotherapies targeting a $\beta$ and tau in Alzheimer's disease. Neurobiology of Disease. 2020; 144: 105010.

[29] Forloni G, Balducci C. Alzheimer's Disease, Oligomers, and Inflammation. Journal of Alzheimer's Disease. 2018; 62: 1261-1276.

[30] Yao J, Rettberg JR, Klosinski LP, Cadenas E, Brinton RD. Shift in brain metabolism in late onset Alzheimer's disease: implications for biomarkers and therapeutic interventions. Molecular Aspects of Medicine. 2011; 32: 247-257.

[31] Wang R, Reddy PH. Role of Glutamate and NMDA Receptors in Alzheimer's Disease. Journal of Alzheimer's Disease. 2017; 57: 1041-1048.

[32] van Marum RJ. Update on the use of memantine in Alzheimer's disease. Neuropsychiatric Disease and Treatment. 2009; 5: 237247.

[33] Reisberg B, Doody R, Stöffler A, Schmitt F, Ferris S, Möbius HJ. Memantine in moderate-to-severe Alzheimer's disease. The New England Journal of Medicine. 2003; 348: 1333-1341.

[34] Autio J, Stenbäck V, Gagnon DD, Leppäluoto J, Herzig KH. (Neuro) Peptides, Physical Activity, and Cognition. Journal of Clinical Medicine. 2020; 9: 2592.

[35] van den Pol AN. Neuropeptide transmission in brain circuits. Neuron. 2012; 76: 98-115.

[36] Sams-Nielsen A, Orskov C, Jansen-Olesen I. Pharmacological evidence for CGRP uptake into perivascular capsaicin sensitive nerve terminals. British Journal of Pharmacology. 2001; 132: 11451153.

[37] Pinhasov A, Nesher E, Gross M, Turgeman G, Kreinin A, Yadid G. The Role of the PACAP Signaling System in Depression. Current Pharmaceutical Design. 2011; 17: 990-1001.

[38] Singh Y, Gupta G, Shrivastava B, Dahiya R, Tiwari J, Ashwathanarayana $M$, et al. Calcitonin gene-related peptide (CGRP): a novel target for Alzheimer's disease. CNS Neuroscience \& Therapeutics. 2017; 23: 457-461.

[39] St-Gelais F, Jomphe C, Trudeau L. The role of neurotensin in central nervous system pathophysiology: what is the evidence? Journal of Psychiatry \& Neuroscience. 2006; 31: 229-245.

[40] Haase N, Herse F, Spallek B, Haase H, Morano I, Qadri F, et al. Amyloid- $\beta$ peptides activate $\alpha 1$-adrenergic cardiovascular receptors. Hypertension. 2013; 62: 966-972.

[41] Niwa K, Porter VA, Kazama K, Cornfield D, Carlson GA, Iadecola C. $\mathrm{A} \beta$-peptides enhance vasoconstriction in cerebral circulation. American Journal of Physiology-Heart and Circulatory Physiology. 2001; 281: H2417-H2424.
[42] Diwakar L, Gowaikar R, Chithanathan K, Gnanabharathi B, Tomar DS, Ravindranath V. Endothelin-1 mediated vasoconstriction leads to memory impairment and synaptic dysfunction. Scientific Reports. 2021; 11: 4868.

[43] Chen X, Du Y, Chen L. Neuropeptides Exert Neuroprotective Effects in Alzheimer's Disease. Frontiers in Molecular Neuroscience. 2019; 11: 493.

[44] Solés-Tarrés I, Cabezas-Llobet N, Vaudry D, Xifró X. Protective Effects of Pituitary Adenylate Cyclase-Activating Polypeptide and Vasoactive Intestinal Peptide Against Cognitive Decline in Neurodegenerative Diseases. Frontiers in Cellular Neuroscience. 2020; 14: 221.

[45] Rat D, Schmitt U, Tippmann F, Dewachter I, Theunis C, Wieczerzak E, et al. Neuropeptide pituitary adenylate cyclaseactivating polypeptide (PACAP) slows down Alzheimer's diseaselike pathology in amyloid precursor protein-transgenic mice. FASEB Journal. 2011; 25: 3208-3218.

[46] de Souza FRO, Ribeiro FM, Lima PMD. Implications of VIP and PACAP in Parkinson's Disease: what do we Know so Far? Current Medicinal Chemistry. 2021; 28: 1703-1715.

[47] Van C, Condro MC, Lov K, Zhu R, Ricaflanca PT, Ko HH, et al. PACAP/PAC1 Regulation of Inflammation via Catecholaminergic Neurons in a Model of Multiple Sclerosis. Journal of Molecular Neuroscience. 2019; 68: 439-451.

[48] Schou WS, Ashina S, Amin FM, Goadsby PJ, Ashina M. Calcitonin gene-related peptide and pain: a systematic review. The Journal of Headache and Pain. 2017; 18: 34.

[49] Charles A. The pathophysiology of migraine: implications for clinical management. The Lancet. Neurology. 2018; 17: 174-182.

[50] Warfvinge K, Edvinsson L, Pickering D, Sheykhzade M. The Presence of Calcitonin Gene-Related Peptide and its Receptors in Rat, Pig and Human Brain: Species Differences in Calcitonin GeneRelated Peptide Pharmacology. Pharmacology. 2019; 104: 332 341.

[51] Hay DL, Garelja ML, Poyner DR, Walker CS. Update on the pharmacology of calcitonin/CGRP family of peptides: IUPHAR Review 25. British Journal of Pharmacology. 2018; 175: 3-17.

[52] Walker CS, Conner AC, Poyner DR, Hay DL. Regulation of signal transduction by calcitonin gene-related peptide receptors. Trends in Pharmacological Sciences. 2010; 31: 476-483.

[53] Russell FA, King R, Smillie S, Kodji X, Brain SD. Calcitonin generelated peptide: physiology and pathophysiology. Physiological Reviews. 2014; 94: 1099-1142.

[54] Rees TA, Gingell J, Siow A, Harris P, Brimble M, Hay D, et al. Differential internalisation of the CGRP and AMY 1 receptor. The FASEB Journal. 2020; 34: 1-1.

[55] Gingell JJ, Hendrikse ER, Hay DL. New Insights into the Regulation of CGRP-Family Receptors. Trends in Pharmacological Sciences. 2019; 40: 71-83.

[56] Routledge SJ, Simms J, Clark A, Yeung HY, Wigglesworth MJ, Dickerson IM, et al. Receptor component protein, an endogenous allosteric modulator of family B G protein coupled receptors. Biochimica Et Biophysica Acta (BBA) - Biomembranes. 2020; 1862: 183174.

[57] Ferrero H, Larrayoz IM, Gil-Bea FJ, Martínez A, Ramírez MJ. Adrenomedullin, a Novel Target for Neurodegenerative Diseases. Molecular Neurobiology. 2018; 55: 8799-8814.

[58] Zhai L, Sakurai T, Kamiyoshi A, Ichikawa-Shindo Y, Kawate H, Tanaka M, et al. Endogenous calcitonin gene-related peptide suppresses ischemic brain injuries and progression of cognitive decline. Journal of Hypertension. 2018; 36: 876-891.

[59] Schebesch K, Herbst A, Bele S, Schödel P, Brawanski A, Stoerr $\mathrm{E}$, et al. Calcitonin-gene related peptide and cerebral vasospasm. Journal of Clinical Neuroscience. 2013; 20: 584-586.

[60] Morton RE, St. John PD, Tyas SL. Migraine and the risk of all-cause dementia, Alzheimer's disease, and vascular dementia: a prospective cohort study in community-dwelling older adults. International Journal of Geriatric Psychiatry. 2019; 34: 1667-1676.

[61] Ringman JM, Romano JD, Medina LD, Rodriguez-Agudelo Y, 
Schaffer B, Varpetian A, et al. Increased prevalence of significant recurrent headache in preclinical familial Alzheimer's disease mutation carriers. Dementia and Geriatric Cognitive Disorders. 2008; 25: 380-384.

[62] Borkum JM. CGRP and Brain Functioning: Cautions for Migraine Treatment. Headache. 2019; 59: 1339-1357.

[63] Vause CV, Durham PL. Calcitonin gene-related peptide differentially regulates gene and protein expression in trigeminal glia cells: findings from array analysis. Neuroscience Letters. 2010; 473: $163-167$.

[64] Harzenetter MD, Novotny AR, Gais P, Molina CA, Altmayr F, Holzmann B. Negative regulation of TLR responses by the neuropeptide CGRP is mediated by the transcriptional repressor ICER. Journal of Immunology. 2007; 179: 607-615.

[65] Rossetti I, Zambusi L, Finardi A, Bodini A, Provini L, Furlan R, et al. Calcitonin gene-related peptide decreases IL-1beta, IL-6 as well as Ym1, Arg1, CD163 expression in a brain tissue contextdependent manner while ameliorating experimental autoimmune encephalomyelitis. Journal of Neuroimmunology. 2018; 323: 94104.

[66] N’Diaye A, Gannesen A, Borrel V, Maillot O, Enault J, Racine P, et al. Substance $P$ and Calcitonin Gene-Related Peptide: Key Regulators of Cutaneous Microbiota Homeostasis. Frontiers in Endocrinology. 2017; 8: 15.

[67] Aresti Sanz J, El Aidy S. Microbiota and gut neuropeptides: a dual action of antimicrobial activity and neuroimmune response. Psychopharmacology. 2019; 236: 1597-1609.

[68] Kovács A, Telegdy G. Effects of CGRP on active avoidance behavior in rats. Physiology \& Behavior. 1995; 58: 429-435.

[69] Angelucci F, Ellenbroek BA, El Khoury A, Mathé AA. CGRP in a gene-environment interaction model for depression: effects of antidepressant treatment. Acta Neuropsychiatrica. 2019; 31: 9399.

[70] Mathé AA, Hertel P, Nomikos GG, Gruber S, Mathé JM, Svensson TH. The psychotomimetic drugs D-amphetamine and phencyclidine release calcitonin gene-related peptide in the limbic forebrain of the rat. Journal of Neuroscience Research. 1996; 46: 316-323.

[71] Wimalawansa SJ, MacIntyre I. The presence of calcitonin generelated peptide in human cerebrospinal fluid. Brain. 1987; 110: 1647-1655.

[72] Mathé AA, Agren H, Lindström L, Theodorsson E. Increased concentration of calcitonin gene-related peptide in cerebrospinal fluid of depressed patients. a possible trait marker of major depressive disorder. Neuroscience Letters. 1994; 182: 138-142.
[73] Mathé AA, Agren H, Wallin A, Blennow K. Calcitonin generelated peptide and calcitonin in the CSF of patients with dementia and depression: possible disease markers. Progress in NeuroPsychopharmacology \& Biological Psychiatry. 2002; 26: 41-48.

[74] Narimatsu N, Harada N, Kurihara H, Nakagata N, Sobue K, Okajima K. Donepezil improves cognitive function in mice by increasing the production of insulin-like growth factor-i in the hippocampus. The Journal of Pharmacology and Experimental Therapeutics. 2009; 330: 2-12.

[75] Knyihár-Csillik E, Boncz I, Sáry G, Nemcsók J, Csillik B. Parabrachial origin of calcitonin gene-related peptideimmunoreactive axons innervating Meynert's basal nucleus. Experimental Neurology. 1999; 157: 268-276.

[76] Csillik B, Rakic P, Knyihár-Csillik E. Peptidergic innervation and the nicotinic acetylcholine receptor in the primate basal nucleus. The European Journal of Neuroscience. 1998; 10: 573-585.

[77] Na H, Gan Q, Mcparland L, Yang JB, Yao H, Tian H, et al. Characterization of the effects of calcitonin gene-related peptide receptor antagonist for Alzheimer's disease. Neuropharmacology. 2020; 168: 108017.

[78] Bowman GL, Dayon L, Kirkland R, Wojcik J, Peyratout G, Severin IC, et al. Blood-brain barrier breakdown, neuroinflammation, and cognitive decline in older adults. Alzheimer's \& Dementia. 2018; 14: $1640-1650$.

[79] Wang E, Zhu H, Wang X, Gower AC, Wallack M, Blusztajn $\mathrm{JK}$, et al. Amylin Treatment Reduces Neuroinflammation and Ameliorates Abnormal Patterns of Gene Expression in the Cerebral Cortex of an Alzheimer's Disease Mouse Model. Journal of Alzheimer's Disease. 2017; 56: 47-61.

[80] Mohamed LA, Zhu H, Mousa YM, Wang E, Qiu WQ, Kaddoumi A. Amylin Enhances Amyloid- $\beta$ Peptide Brain to Blood Efflux across the Blood-Brain Barrier. Journal of Alzheimer's Disease. 2017; 56: 1087-1099.

[81] Hay DL, Chen S, Lutz TA, Parkes DG, Roth JD. Amylin: Pharmacology, Physiology, and Clinical Potential. Pharmacological Reviews. 2015; 67: 564-600.

[82] Palmiter RD. The Parabrachial Nucleus: CGRP Neurons Function as a General Alarm. Trends in Neurosciences. 2018; 41: 280-293.

[83] Saido T, Leissring MA. Proteolytic degradation of amyloid $\beta$ protein. Cold Spring Harbor Perspectives in Medicine. 2011; 2: a006379.

[84] Bennett RG, Duckworth WC, Hamel FG. Degradation of Amylin by Insulin-degrading Enzyme. Journal of Biological Chemistry. 2000; 275: 36621-36625. 